\title{
Retesting the anti-doping samples: Best tool for deterrence?
}

\author{
Kuuranne $T^{1}$ and Saugy $M^{2}$ \\ 1 Swiss Laboratory for Doping Analyses, University Center of Legal Medicine Lausanne-Geneva, Centre Hospitalier Universitaire \\ Vaudois and University of Lausanne Chemin des Croisettes 22, 1066 Epalinges, Switzerland \\ ${ }^{2}$ Center for Research and Expertise for anti-Doping Sciences (REDs), Institute of Sports Sciences of the University of Lausanne, \\ Geopolis, 1015 Lausanne, Switzerland
}

\begin{abstract}
Long term storage of the anti-doping samples and their reanalyses becomes today more and more a trend in the anti-doping community. The procedure has been implemented by the anti-doping authorities for the samples of the Tour de France and for the Olympic Games since Athens 2004 and has been always presented as a good tool to deter doping habits in top level sport.

Recently, the World Anti-Doping Code introduced the possibility for anti-doping organizations to store the athletes' samples up to ten years. The anti-doping authorities may ask to reanalyze the samples at any time during that period of time as a function of the implementation of new methods or instruments in the accredited laboratories allowing the detection of prohibited substances or their metabolites at a much lower concentration or for a larger detection window. The most significant technological advances for the detection of doping substances have been done in the characterization of various long-term metabolites of anabolic androgenic steroids. This allowed for increasing the time of detection by even a factor of four.
\end{abstract}

Keywords:

sport, World Anti-Doping Agency (WADA), anabolic androgenic steroids, doping, prohibited list

\section{Résumé}

Le stockage à long terme des échantillons anti-dopage, ainsi que leurs ré-analyses sont de plus en plus prisé par la communauté anti-dopage. Cette procédure de conservation des échantillons avait d'abord été mise en place par les autorités anti-dopage pour le Tour de France, puis pour les Jeux Olympiques depuis ceux d'Athènes en 2004. Ceci a toujours été présenté comme bon outil de dissuasion pour lutter contre les habitudes de dopage dans le sport de haut niveau.

Récemment, le Code Mondial Antidopage a introduit la possibilité pour les organisations antidopage de conserver les échantillons des athlètes jusqu'à dix ans.

Ainsi, ces organisations peuvent demander à tout moment pendant cette période de ré-analyser les échantillons conservés, en fonction de l'introduction de nouvelles méthodes d'analyse ou de nouveaux instruments dans les laboratoires antidopage. Ceci doit permettre de détecter les substances interdites (ou leurs métabolites) à des concentrations plus basses, augmentant de ce fait leur fenêtre de détection. Récemment, les avances technologiques les plus significatives ont été faites dans la caractérisation des plusieurs métabolites à long terme de stéroïdes androgènes anabolisants. Ceci a permis d'augmenter par un facteur quatre le temps de détection de ces substances.

Mots clés:

Sport, Agence Mondiale Anti-dopage (AMA), stéroïdes anabolisants androgènes, dopage, liste des produits interdits 


\section{Introduction}

Since the end of the nineties, all anti-doping urine samples collected during the Tour de France are stored for long term by the French anti-doping authorities. The urine samples from Tour de France 1999 were reanalyzed in 2005 for the detection of EPO and in several cases synthetic EPO was detected. This new method, invented by the Châtenay Malabry Laboratory [1] has been officially implemented for the first time during the Sydney Olympic Games in 2000. At the time, this example was one of the most spectacular applications of the principle of long term storage and reanalysis with a new or improved technology.

In 2004, the recommendation of the new World Anti-doping Code (2003) was implemented in the anti-doping rules of the International Olympic Committee (IOC) and for the Athens Olympic Games all the anti-doping samples were stored frozen for long term up to eight years.

At the level of the Olympic Games, the first operation of reanalyses was done in 2009, six months after the 2008 Beijing Games. A new method for the detection of C.E.R.A. (Continuous Erythropoetin Receptor Activator, third generation EPO) was implemented soon after the Games by two laboratories $[2,3]$ and they were requested to reanalyze all the serum samples collected during the Games. As the outcome of this operation of retesting, seven cases (corresponding to six athletes) were found positive for C.E.R.A.

In 2012, the IOC ordered several reanalyses concerning the 2004 Athens samples, due to significant improvements in the analytical methods which were implemented within this timeframe in the laboratories accredited by the World Anti-Doping Agency (WADA). The new methods allowed for dramatic extension of the detection time window of several prohibited substances and their representative metabolites. After these pioneering operations several retests have been done from other Olympic Games and major competitions.

\section{World anti-doping code and international standards}

The 2015 World Anti-Doping Code allows for the storage of samples for up to 10 years, which markedly transforms the anti-doping environment as the retesting with newly designed analytical methods is considered as very important and powerful tool for the deterrence effect [4]. The new 2015 International Standard on Testing and Investigations [5] sets out the requirements for anti-doping organizations (ADOs) to test, store and reanalyze samples. The responsibility for setting the priorities and selection of samples for the long-term storage is the responsibility of the ADOs, e.g. international federations (IFs) and national anti-doping agencies (NADOs), and based on their risk assessment. For the success of retesting, it is important that the storage of samples is conducted in a manner that enables application of future methods that may not yet be fully developed or operational.

These conditions are extensively described by the International Standard for Laboratories [6] (ISL, 2015, \# 5.2.2.12 Long term storage of samples) and the duties of testing authorities and laboratories can be summarized as follows:

- Any sample may be stored in long-term storage for up to ten years.
- The testing authority should retain the official doping control records for the duration of sample storage.

- The laboratory should retain all chain of custody documents for the duration of sample storage.

- If samples are to be stored at a location outside the secured area of the laboratory which first analyzed the sample, the laboratory shall secure the A- samples to be shipped in a manner which ensures integrity and chain of custody of the sample.

- During transport and long-term storage, samples shall be maintained at a temperature sufficient to maintain the analytical integrity of the sample.

- The long-term storage facility shall maintain security requirements comparable to the security requirements applicable to short-term storage facilities in the laboratory.

- Samples held in long-term storage may be selected for reanalysis at the discretion of the testing authority or WADA.

- Further analysis on long-term stored samples shall proceed by taking all necessary precautions in order to preserve the quality of the analyses and the rights of the athlete. If the full initial testing and confirmation procedure is not completed on the A-sample, the testing authority shall appoint an independent witness to verify the opening and splitting of the sealed B-sample and then proceed to analysis based on the B-sample which has been split into 2 bottles.

\section{Long term storage conditions and costs}

Logistics and maintenance of the long-term storage requires laboratory resources, and depending on the number of samples and the time period, the costs can be significant and exponential. Among the ADOs and event organizers the operational environment may vary greatly and especially with limited budgets it is necessary to build up a strategy in order to keep only the prioritized samples and to control the costs of long-term storage. These strategies must certainly be based on intelligence, which is derived from non-analytical and analytical information accompanied by specific risk assessment.

\section{What to retest and when?}

Even if the ADOs have been given the right to retest the samples up to 10 years after the collection, it is not necessarily the best option to wait with the analysis until the very end of that period.

Whichever will the timeline be, the key element of retesting is certainly the capability to apply new methodologies or to take the advantage of significant improvements in the detection methods.

In general, the improvements are due to major technical steps in the instrument development, which may either enable discovery of new types of target compounds or increase the sensitivity and the specificity of the detection. As a result of these advances new metabolites can be discovered and also the detection time window of traditional metabolites can be dramatically increased. 


\section{The cases of AAS}

The first significant advance in the long-term detection has been reached with anabolic androgenic steroids (AAS), which are among the most frequently detected drugs in amateur and professional sports. One of the first steps in that direction was done in Cologne [7] with respect to pharmacokinetics and excretion profiles of metandienone and its metabolites. A new metandienone metabolite (18-nor-17betahydroxymethyl,17alpha-methyl-androst-1,4,13-trien-3-one) was identified by the Cologne team in excretion study urine samples. This new metabolite was characterized using gas chromatography/(tandem) mass spectrometry, liquid chromatography/tandem mass spectrometry and liquid chromatography/high-resolution/high-accuracy (tandem) mass spectrometry.

The 18-Nor-17beta-hydroxymethyl,17alpha-methyl-androst-1,4,13-trien-3-one was determined in metandienone administration study urine specimens up to 19 days after application of a single dose of $5 \mathrm{mg}$, hence providing an extended detection period compared with commonly employed strategies. This observation provided a valuable tool for the long-term detection of metandienone abuse by athletes in sports drug testing and resulted in an increase of adverse analytical findings (AAFs) of metandienone for more than $400 \%$ from approximately 12-15 AAFs in the years 20032005 to 68 AAFs in 2006, although the number and origin of the analyzed samples was nearly constant [8].

The same group of researchers applied similar strategies by using the benefits of instrument development to improve the detection of other steroids, apparently widely used by top-level athletes. The group was able to enhance the analytical possibilities to detect stanozolol misuse by the detection of stanozolol glucuronides [9] and of oxandrolone [10].

Another step forward in the detection of a widely used steroid, dehydrochloro-methyltestosterone ("Oral-Turinabol"), was taken by Russian laboratory [11] for the detection and the characterization of novel urinary long-term metabolites and the results of their study have extended the detection time of this particular substance in a significant manner. According to a practical example provided by the laboratory, inclusion of the novel metabolite to the routine analysis resulted in 15 adverse analytical finding whereas only five of the cases could have been detected by monitoring only two more traditional metabolites.

\section{Result management}

There are several important issues related to the reporting from the laboratory and for the result management by the anti-doping organization.

\section{Which list of prohibited substances is applicable?}

The date of sample collection defines the list of prohibited substances for the reanalysis. Consequently, e.g. the reanalyses performed on the samples from the IAAF World Championships held in 2007 in Osaka (JPN) are based on the 2007 WADA list of prohibited substances. Nevertheless, it is important to know that for the most categories of substances the list is constructed as open, i.e. any other substances with a similar chemical structure or similar biological effect(s) will be analogously recognized as prohibited. For example, in the prohibited list 2007, many substances are cited as examples in the category "S1.1.a Exogenous Anabolic Androgenic Steroids". This means that any new designer steroid which was used in 2007 without being detectable by the anti-doping laboratory at the time of the competition could be potentially reported as an AAF if detected in the stored samples when analyzed less than 8 years after.

\section{What is the ideal timeframe for the reanalyses?}

Several points must be taken into consideration when the decision is made for an ideal timeframe for the retesting. The entire technical process is time-consuming: starting from the administrative work of locating the samples among different laboratories, and ending with B-split or B-sample analysis with the obligation to preserve the rights of the athlete. The rules define the possibility for the athlete to witness the B-split or the B-analysis. Eight or ten years after a major competition, it may be difficult to reach the athlete or to motivate participation in such a procedure. Consequently, there will be a question of a reasonable effort by the anti-doping organization to reach the athlete and it is certainly a legal issue, which must be better defined in the future to improve the flow of the procedure. For example, should it be necessary, or even possible, to keep in a specific database all the whereabouts information of the athletes who have already retired from active career or who are otherwise difficult to reach?

\section{Communication and deterrence effect}

The timeline defined for the retesting and the quality of the communication of the results are the two key issues to obtain the best deterrence effect of any operations of reanalyses. On one hand, it is obviously necessary to wait for a certain period of time to allow the laboratories to develop new or more sensitive detection methods. But on the other hand, if the retest is performed very long time after the initial competition dates (10 years is quite long in the sport's perspective), the audience could be a completely new generation of athletes and the deterrence effect could be decayed.

There is always also the question if the negative reanalysis results could not definitively validate the results of those athletes eight or ten years after the competition. Whichever a percentage of adverse analytical findings is returned from the reanalysis process (e.g. 10\%), a high number of samples will be then declared negative (in our case 90\%). The outcome could be also supportive to these athletes who could validate their results or medal.

\section{Conclusion \& perspectives}

There are many factors to take into account for the strategy and execution of reanalyses. To our opinion, in order to reach a successful outcome, it is necessary to establish a dialog between all the operators. Representatives of the anti-doping organizations, athlete community, anti-doping laboratories and disciplinary panels must have regular contact to define the best strategies in specific context. In the fight against doping, it is accepted to harmonize the rules for the integrity 
and equity in sport and to protect the clean athletes. However, it must be also acknowledged that the tools used for the implementation of these principles must evolve quickly in a proactive manner and the reanalyses of long term stored samples must be seen in this perspective.

\section{Corresponding author}

Martial Saugy, PhD, Associate Professor. Director

Center for Research and Expertise for anti-Doping Sciences (REDs), Institute of Sports Sciences of the University of Lausanne, Geopolis, 1015 Lausanne, Switzerland martial.saugy@chuv.ch Tel. +41 795562784

\section{References}

1. Lasne F, de Ceaurriz J. Recombinant erythropietin in urine. Nature 2000;405(6787):635.

2. Lamon S, Giraud S, Egli L, Smolander J, Jarsch M, Stubenrauch KG, Hellwig A, Saugy M, Robinson N. A high-throughput test to detect C.E.R.A. doping in blood. J Pharm Biomed Anal. 2009;50(5):954-8.

3. Lasne F, Martin L, Martin JA, de Ceaurriz J. Detection of continuous erythropoietin receptor activator in blood and urine in anti-doping control. Haematologica. 2009;94(6):888-90.
4. Dvorak J, et al. Time for change: a roadmap to guide the implementation of the World Anti-Doping Code 2015. Br J Sports Med 2014;48:801-806.

5. WADA. International standards: Testing and Investigation January 2015, https://wada-main-prod.s3.amazonaws.com/resources/files/ WADA-2015-ISTI-Final-EN.pdf (accessed 09.09.2016)

6. WADA. International standards: Laboratories January 2015. https:// wada-main-prod.s3.amazonaws.com/resources/files/WADA-ISL2015-Final-v8.0-EN.pdf (accessed 09.09.2016)

7. Schänzer W, Geyer H, Fusshöller G, Halatcheva N, Kohler M, Parr MK, Guddat S, Thomas A, Thevis M. Mass spectrometric identification and characterization of a new long-term metabolite of metandienone in human urine. Rapid Commun Mass Spectrom. 2006;20(15):2252-8.

8. Thevis M. Anabolic agents: recent strategies for their detection and protection from inadvertent doping. $\mathrm{Br} \mathrm{J}$ Sports Med. 2014;48(10):820-6.

9. Schänzer W, Guddat S, Thomas A, Opfermann G, Geyer H, Thevis M. Expanding analytical possibilities concerning the detection of stanozolol misuse by means of high resolution/high accuracy mass spectrometric detection of stanozolol glucuronides in human sports drug testing.Drug Test Anal. 2013;5(11-12):810-8.

10. Guddat S, Fußhöller G, Beuck S, Thomas A, Geyer H, Rydevik A, Bondesson U, Hedeland M, Lagojda A, Schänzer W, Thevis M. Synthesis, characterization, and detection of new oxandrolone metabolites as long-term markers in sports drug testing. Anal Bioanal Chem. 2013;405(25):8285-94.

11. Sobolevsky T, Rodchenkov G. Detection and mass spectrometric characterization of novel long-term dehydrochloromethyltestosterone metabolites in human urine. J Steroid Biochem Mol Biol. 2012; 128(3-5):121-7. 